\title{
Dinheiro, de Victoria Benedictsson: Uma tradução a quatro mãos e quatro línguas
}

\author{
Astrid Adelgren ${ }^{1}$ \\ Marina Darmaros ${ }^{2}$
}

\begin{abstract}
Resumo: Victoria Benedictsson foi uma das figuras-chaves do "Grande Avanço Moderno" sueco, que precedeu mudanças essenciais para que a sociedade escandinava se tornasse mais igualitária - e uma das mais igualitárias do mundo - em termos de gênero. O trecho do romance Pengar ("Dinheiro") vertido aqui pela primeira vez ao português brasileiro é fundamental para se compreender também o pensamento da autora e seu suicídio, que destituiu a cena literária e feminista prematuramente de um de seus ícones.
\end{abstract}

Palavras-Chave: tradução, estudos da tradução, literatura sueca, literatura feminina, Grande Avanço Moderno, literatura escandinava, Victoria Benedictsson

\section{Introdução}

A autora escolhida para esta tradução, Victoria Benedictsson, é uma das escritoras suecas mais estudadas da década de 1880 (Nordenstam, 2008: 427). Ainda em vida, alguns de seus trabalhos foram vertidos para o alemão, dinamarquês e holandês. Postumamente, ela foi traduzida também para outras línguas

1 Astrid Adelgren é bacharel em Ciências Políticas pela Universidade de Lund, jornalista pela Escola de Jornalismo de Skurup e pela Folkhögskola de Biskops Arnö-Nordens e pesquisadora em Escrita Criativa pela Universidade de Södertörn. Contato: astrid.adelgren@gmail.com.

2 Marina Darmaros é doutoranda do programa de Cultura e Literatura Russa da USP, mestra em Jornalismo Internacional pela Universidade Estatal Russa da Amizade dos Povos e bacharel em Jornalismo pela Faculdade Cásper Líbero. Contato: marina.darmaros@usp.br. 
escandinavas, assim como para o russo, o inglês e o húngaro (Holm, 2008a). Entretanto, seu trabalho não recebeu a devida atenção fora das fronteiras suecas (Moberg, 2007: 380).

Benedictsson cresceu no interior do condado de Skåne, e desde cedo sonhava em partir rumo a Estocolmo para estudar na academia de artes. Mas seu pai não permitiu que ela realizasse esse sonho, e, em sinal de protesto, ela noivou com um homem muito mais velho, o viúvo Christian Benedictsson, que tinha 28 anos a mais que ela e cinco filhos.

Mais tarde, Benedictsson pôs em dúvida o noivado, mas não quis desfazê-lo sem o total consentimento do noivo, e assim, em 1871, casou-se com ele (Holm, 2008b; Hjort, 1969:5).

Na segunda metade do século 19, a Suécia ainda era um país extremamente patriarcal. Uma mulher não podia se casar sem o consentimento do pai, e, quando casada, era entendida como menor de idade, tanto na relação como dentro de casa. O homem era o único guardião legal dos filhos, e também tinha o direito de administrar a propriedade da mulher ${ }^{3}$.

A situação das mulheres começou a mudar, ainda que lentamente, nesse período. A industrialização criou oportunidades de trabalho. Ao mesmo tempo, o índice de casamentos diminuiu - o que se deu, em parte, devido ao fato de haver um excedente feminino. Tudo isso resultou em que muito mais mulheres começassem a trabalhar fora de casa para se manter (Heggestad, 1991: 9, 24).

O que se esperava desse novo papel das mulheres nesse período de mudanças foi assunto de muita discussão pública. Esse debate também era amplamente visível na literatura, uma cena que passou a contar com a participação de muito mais mulheres que antes (Heggestad, 1991: 9-10), sobretudo com o "Grande Avanço Moderno" ", importante não só para Benedictsson, mas para muitas outras escritoras, como Anne Charlotte Leffler e Alfhild Agrell. Essas foram responsáveis por escrever sobre a sociedade em uma tradição realista e naturalista, e seus livros focam a situação da mulher (Willemsen 2012: 7).

3 Essas condições tiveram uma leve melhora em 1874, quando a mulher passou a ter o direito de exigir um acordo pré-nupcial (Heggestad, 1991: 18).

4 "Det moderna genombrottet" foi um forte movimento de naturalismo e debate literário na Escandinávia, ocorrido concomitantemente na Noruega ("Det moderne gjennombrudd"), na Dinamarca ("Det moderne gennembrud") e na Suécia ("Det moderna genombrottet"). Substituiu o Romantismo em finais do século XIX. 
Victoria Benedictsson fez parte desse movimento. Uma das figuras-chaves do "Grande Avanço Moderno", ela focava o papel da mulher na sociedade por meio de uma tradição naturalista e realista (Willemsen, 2012: 7; Holm, 2007: 119120). Como colocado pela pesquisadora Yvonne Leffler, a ficção pode ter sido o caminho encontrado por essas escritoras para, de maneira mais implícita, terem suas vozes ouvidas no debate (Willemsen, 2012: 16). Ainda assim, essa literatura era vista por muitos como controversa (Ibid, 2012: 8).

Pengar ("Dinheiro") foi o primeiro romance de Benedictsson, e um de seus mais conhecidos, publicado em 1885 sob o pseudônimo de Ernst Ahlgren, que a autora usava frequentemente. O título conta a história de uma jovem chamada Selma que, como a própria escritora, sonha em se mudar para Estocolmo para estudar artes. Seu tio, porém, a convence a se casar com o rico Pål, mais velho, quando ela tem apenas 16 anos. Assim, ela passa a ter dinheiro - mas não liberdade - e um casamento infeliz.

O casamento se mostra desafortunado não apenas porque ela não está apaixonada pelo marido. Agora ela tem dinheiro, mas sente que sua vida não tem sentido. Ela almeja tornar-se independente e lutar em nome de uma causa:

E ela mesma - ela não tinha exatamente aquilo pelo que os outros lutam por meio do trabalho? Dinheiro... Dinheiro? Que palavra pobre! Dinheiro, mas nada pelo que lutar. Não, combater com a vida, lutar por seu pão, isso é viver. Ela passou a mão devagar pela testa. Vegetar e morrer, isso era um dever, claro - para ela (Benedictsson, 1969: 138) ${ }^{5}$.

No final, ela decide que quer se separar do marido, apesar de hesitar quando esse explica que não há "nenhum caminho, nenhum futuro" para ela sozinha, já que Selma não tem educação formal ou qualquer experiência de trabalho (Benedictsson, 1969: 151).

Apesar disso, a protagonista está determinada na última cena a deixar sua vida de casada, e escreve uma carta pedindo ao primo que a ajude a encontrar um trabalho na Alemanha.

O livro é uma forte crítica à sociedade desse período, que tornava aceitável, legal e moralmente, esse tipo de casamento, e foi visto como um romance de emancipação (Forsås Scott, 1997: 25; Nordenstam, 2008: 427).

5 “Och hon själv, ägde hon ej just vad andra eftersträva med sitt arbete? Pengar... Pengar? Vilket fattigt ord! Pengar men ingen strävan. Nej, kämpa med livet, slåss om brödet, det är att leva. Hon strök sig långsamt över pannan. Vegetera och dö, det var ju plikten - för henne.” 


\section{Benedictsson no cenário atual}

Pengar e outras obras de Benedictsson nem sempre foram itens obrigatórios dos currículos escolares suecos, como aconteceu a livros de autores como August Strindberg, da primeira mulher a receber o Nobel de Literatura, Selma Lagerlöf, e de Hjalmar Söderberg. Mas, como já dito, seus trabalhos foram amplamente analisados e discutidos e seus livros são considerados clássicos (Kalmteg, 2008).

$\mathrm{Na}$ atualidade, porém, a maior parte dos jovens suecos que ingressam na educação pré-universitária (o chamado "gymnasium") têm contato com a obra de Benedictsson, que é geralmente apresentada como uma das autoras que escreveram sobre a "kvinnofrågan", ou seja, a "questão feminina".

Assim, Benedictsson continua em voga e é assunto na cultura e no debate contemporâneo - talvez tanto por sua própria história de vida quanto por sua escrita. A autora feminista de quadrinhos Liv Strömqvist, por exemplo, escreveu de maneira satírica em Prins Charles Känsla (2010) sobre a trágica relação de Benedictsson com o crítico literário dinamarquês George Brandes ${ }^{6}$, que teria sido um dos motivos do suicídio da escritora em um hotel de Copenhague quando ela tinha apenas 33 anos de idade (Strömqvist, 2010: 93-100; Holm, 2008b). Brandes queria um relacionamento baseado no "amor livre" com a escritora, o que parece ter sido a centelha que destruiu a relação. Ela escreve ostensivamente sobre o assunto em seu diário.

O monólogo Ni kan kalla mig Ernst ("Pode me chamar de Ernst"), que esteve em cartaz entre 2017 e 2018 no teatro público de Malmö, também foca o trágico suicídio de Benedictsson.

Há alguns anos, também se reacendeu o debate público sobre se a Academia Sueca teria agido corretamente ao publicar obras de Benedictsson em um formato editado e distorcido pelo escritor Axel Lundergård após a morte daquela (Kalmteg, 2008). A relação da autora com seu colega Lundergård e o significado desse contato em sua obra foi objeto de discussão repetidas vezes. Os dois trabalharam em estreita colaboração e Benedictsson legou seus direitos literários a Lundergård, entre eles, o direito de que esse revisasse suas obras.

6 Brandes é considerado o fio condutor por trás do "Grande Avanço Moderno", apesar de alguns escritores já começarem a escrever em estilo realista antes de sua formulação do paradigma estético do movimento. Suas palestras na Universidade de Copenhague a partir de 1871 e seu trabalho Hovedstromninger i det 19. Aarbundredes Litteratur ("Principais Correntes na Literatura do Século 19") marcam o início do período. 
Obras como Pengar são, ainda hoje, relevantes para a sociedade sueca de outras formas menos discutidas. Muito se passou, obviamente, desde que Pengar foi escrito. Agora, mulheres e homens têm os mesmos direitos legais dentro do casamento: de acordo com a lei, não se pode obrigar alguém a casar a força ou casar sendo menor de idade. Além disso, é crime forçar alguém a casar, mesmo de maneira mais implícita (Länsstyrelsen Östergötland 2017a).

Fora do papel, porém, o cenário sueco é um pouco diferente, já que muitas moças (e rapazes) têm pouca influência na decisão de seu próprio futuro, com quem casarão e quando. Há casos também de casamentos forçados - algo que as autoridades suecas fracassaram em impedir repetidas vezes (Länsstyrelsen Östergötland, 2017b) ${ }^{7}$.

Como muitos outros clássicos, Pengar também coloca questões mais universais relevantes a qualquer tempo e espaço - por exemplo, como se tornar um ser humano livre e quais as implicações reais disso.

Conquanto outras obras de Benedictsson também sejam dignas de nota, Pengar foi a que mais nos impressionou, com seus diálogos tão realistas que quase se pode ouvi-los ao lê-los - especialmente aqueles de Selma com o primo. Há também nesse romance algo acerca do desespero e do amargor reprimido da protagonista em relação ao casamento, e a situação em que essa se encontra soa tão verdadeiro e genuíno que nos remete à situação das mulheres que, ao longo da história em geral (e ainda hoje) passam por situações semelhantes.

Dessa forma, em nossa opinião, a obra de Benedictsson merece mais atenção - e isso também fora dos limites suecos.

\section{Notas sobre a tradução}

A presente tradução nasceu dos esforços conjuntos da tradutora sueca de espanhol Astrid Adelgren e da tradutora brasileira do russo e inglês Marina Darmaros. Mas reduzir este trabalho a uma parceria apenas não estaria correto, uma vez que toda a pesquisa bibliográfica, escolha dos textos e versão inicial em espanhol foram levadas a cabo por Astrid Adelgren.

O texto apresentado a seguir, um trecho escolhido do último capítulo de Pengar, de Victoria Benedictsson, foi vertido inicialmente do sueco ao espanhol

7 Há apenas dois anos e meio, a lei foi revisada para impedir casamentos forçados e casamentos infantis, mas até então apenas uma pessoa foi sentenciada (Gabelic et al 2017). 
por Adelgren e então ao português por Darmaros, cotejado com o inglês e discutido através de um sem-número de contatos entre as tradutoras acerca de termos específicos e estilo. Algumas das especificidades dessa tradução a partir do sueco constam nas notas de rodapé. 


\section{Pengar - Kapitel 10}

Victoria Benedictsson

- Varför är lagen så orättvis, att en man icke får gifta sig förrän vid tjuguett år, och en kvinna redan vid sexton ? sade hon plötsligt.

- Lagen vill vara artig mot damerna.

- $\AA$ nej, utbrast hon otåligt och slog sakta med solfjädern mot sitt knä, jag menar inte så! Jag menar, att inte heller vi borde få gifta oss förrän vi bleve myndiga.

- Kvinnan är förr vuxen än mannen.

- Jaså. Är hon förr vuxen till att ta sin egen framtid om händer? Det har jag aldrig vetat.

- Och så finns det många, som ha lust att gifta sig innan de fyllt tjuguett år. Du själv till exempel. Han nickade godmodigt och höjde sitt ölglas.

- Därför behövde lagen ändras.

- Man har givit den omyndiga kvinnan det skyddet, att hon är beroende av sin giftomans samtvcke.

- Men hur i all världen skall en giftoman kunna avgöra om hon kan känna någon livsgemenskap med den man som friar till henne, när hon inte vet det själv ännu ? Ja, när hon inte ens kan sägas ha ctt verkligt livsinnehåll.

- Livsinnehåll? Prat! Hur många fruntimmer leva inte tills de nå sina sextio år, utan att ha något livsinnehåll för det? Moderna fraser! Låt dem gifta sig först, så kommer nog livsinnehållet: - hus, och hem att styra om. Du har ju sett med dig själv.

- Hus och hem skulle styras bättre, om kvinnorna finge använda de där fyra, fem åren till att lära sig vad som erfordras, sade hon, lyfte tlpp handen och stödde huvudet däri, medan hon betraktade honom med något av den uttråkade resignation, varmed man fullföljer ett arbete, som man redan länge känt vara gagnlöst, men dock anser sig skyldig att bringa till slut; dessutom glömmer du alldeles hur rika för ens inre utveckling just de åren mellan sexton och tjugu bruka vara.

Det tycktes henne som hade de fört detta samtal hundra gangcr förut, fast det var ett ämne som hon nu först bragt å bane. Men det kom väl av att hon kände hans tankar, så som man känner den bok man lärt utantill: innan frågan är uttalad vet man hur svaret skall Iyda.

- Du glömmer att det ibland finns fall, då ett skyndsamt giftermål... Patronen hostade. 
- Det är icke för undantagsfall man skriver lagar. Och det, att någonting sådant kan inträffa, bör icke föranleda lagen att låta två andligen omyndiga varelser binda sig vid varandra för ett helt langt liv. Jag står kvar vid min fråga.

- Men du kan väl inte neka till, att kvinnan i allmänhet är tidigare utvecklad än mannen?

- I intellektuellt avseende är hon det för ingen del. Åtminstone inte under nu rådande uppfostringssätt. Brådmogen blir hon. Men det är också allt. Hon tänker alltid på att hon är stora damen. Att hon kan bli fru vilken dag som helst. Selma gjorde en grimas.

- Jag vet inte vad du kan ha att säga. Själv var du bara sexton år, när du gifte dig, och det avlopp så bra.

Hon blev flammande röd och rätade upp sig på stolen.

- Jag tycker att du bara behöver tänka på vilket oting jag var, för att inse det bakvända i saken, svarade hon skarpt.

- För mig var du ett riktigt förtjusande litet oting, och när man ser på dig nu, har man svårt att tro tidiga giftermål vara till skada. Du har sannerligen vuxit till dig. Han såg på henne med något av förtjusningen hos en sportsman, som betraktar en elegant rashäst.

- Det där skulle du aldrig ha nämnt! Hon reste sig upp och kastade solfjädern ifrån sig på spegelbordet, så att den med ett rasslande ljud föll mot dess blanka skiva. Nu var samtalet nytt, ty nu var lugnet förbi. Inte till skada - å! - inte till skada? Vad tyckte du att jag var, när vi gifte oss? Ett stackars barn, som varken kände människorna eller sig själv, som inte visste vad hon gick till och som var färdig att hålla av hela världen, därför att hon såg på allt med samma naiva okunnighet. Säg, tyckte du aldrig att det var synd om mig? Jag hade ju inte som andra en mor, som kunde säga mig ...

- Tror du att mödrar tala om sådant?

Patronen petade likgiltigt sina tänder.

- Det måtte väl vara deras skyldighet! Hon såg på honom med förvåning.

- Skulle du uppfostrat dina barn på det viset, så gjorde vår Herre bäst $\mathrm{i}$ att inte låta dig få nagra, sade patronen och lade den skrynkliga servetten ifran sig med en knyck, det anses väl annars vara mödrars skyldighet att låta sina döttrar växa upp så rent och ...

- A, utstötte hon strävt, jag orkar inte höra mer. Har jag inte den gränslösaste avsky för allt smutsigt, just därför att jag vet hur smutsigt det är! Förut visste jag det ju inte. A, det är ett elände! Man går och målar ut allting så vackert för sig - idel blommor och solsken och man tror att allting är likt ens eget sinne! $\AA$ gud ! ... man är ju som människorna före syndafallet - så dum och Iycklig. Man förstår inte att skilja mellan gott och ont.

- Ja, för man skulle väl ha reda på allting, precis som... Han talade vresigt och började bli förargad.

- ... precis som ni, ifyllde hon. Ja, ackurat.

Det kom så avgörande, med något av den gamla tonen. 
- Nej du, någon moral måste finnas, sade han överlägset och tande sin cigarr.

- Ja. Densamma för oss som för er.

Patronen bara sög eld på sin cigarr. Det var ju en orimlighet hon där kom med igen, men det föll sig lite svårt att säga henne det just nu. Med fruntimmer kommer man aldrig någon vart, de skola alltid ha sista ordet. Han visste också av gammalt, att när hon en gång högg tag, så bruka de hon hålla fast. Resoneman get ingav en viss känsla av obehag. Han skulle helst önskat att vika undan.

- När du gifte dig med mig, var jag omyndig, sade hon. Själsspanningen kom hennes hjärta att klappa i flygande hast, men orden voro livlösa som en lagparagraf; så hade hon vänt och vridit dem i sitt sinne. En skuldsedel av mig skulle icke varit giltig, och ingen annan ägde rätt att i mitt namn utfärda en sadan på så mycket som ett öre, icke heller att skänka bort något av det som i framtiden skullc bli mitt. Min person är mer än mina pengar. Var jag icke mogen att förvalta dem, så var jag det långt mindre när det gällde att förfoga över mig själv. En omyndig bör lika litet få bortpanta sin framtid som sin egendom. Den logiken är enkel.

- Ja, seså, låt oss nu inte bråka. Du är vid dåligt humör. Kom och drick ett glas champagne, så går det över.

- Nej. Jag vill inte ha din champagne, sade hon hårt. Det hade varit henne vidrigt i alla fall, men att han kunde komma med det just nu, då hon för första gången talade om vad som jäst inom henne under åratal, det endast ökade bitterheten.

Men han kände sig mätt och varm, och då han endast helt förstrött följt med vad hon sagt, kunde kan icke veta vad som låg i luften.

- Jo, du är trött, envisades han, drick, det livar upp. Och druvor! Det plär du ju tycka om.

- Låt bli. Jag smakar det inte.

Han svarade ej, utan lossade för korken och lät den flyga upp med en knall. Hon stod orörlig kvar vid Iönstret och betraktade honom, det slog sig två fina veck mellan ögonbrynen, som det alltid gjorde när hon blev ond. Patronen slog upp i båda glasen, gick sedan fram och ville räcka henne det ena, men hon stötte undan hans hand så häftigt, att han spillde en del av vinet.

- Hur bär du dig åt! sade han harmset, satte hennes glas tillbaka på bordet och tömde sitt eget. Men så lade han band på sig, ty med ondo gjordes hon bara istadigare, det visste han.

- Sedan han letat rätt på korken och bultat den i flaskan igen, satte han sig borta i gungstolen, så att han kunde se henne. Sinnesrörelsen hade återgivit hennes kinder denna skarpt begränsade rodnad, som kom det att se ut som vore hon lätt sminkad. Han fann henne vacker. Det var denna friskhet, som ...

Hon tänkte blott, att det icke finns någonting mera motbjudande än att se ungdomens passioner gå och spöka i ett gammalt ansikte. 
- Du har blivit kall och förfrusen, kom, så skall jag värma dig, sade han och bredde ut sina armar, medan han helt sirligt höl] cigarren mellan pek- och långfingret.

- Det var just det jag ville säga, att det löfte, jag gav som barn, icke är bindande för mig som kvinna.

- Vad är det för prat!

- Jag kan inte längre - förstår du - det är slut. 


\section{Dinheiro - Capítulo 10}

Victoria Benedictsson

Tradução do sueco:

Astrid Adelgren

Marina Darmaros

(...)

- Por que é que a lei é tão injusta que um homem não ${ }^{8}$ tem permissão para se casar até ter vinte e um anos, enquanto uma mulher pode fazê-lo já aos dezesseis anos? - disse de repente.

- A lei quer ser mais cortesa com as damas.

- Ah, não! - ela exclamou impacientemente e bateu lentamente o leque sobre o joelho. - Não é o que quero dizer! O que quero dizer é que nós também não deveríamos ter permissão para nos casar antes de atingir ${ }^{9}$ a maioridade.

- A mulher se torna adulta antes do homem.

- Ah, sim. Ela é adulta antes para ter seu próprio futuro nas suas mãos? Não sabia.

- E há muitas que querem se casar antes de completar os vinte e um anos. Tu mesma, por exemplo - ele disse, fazendo um gesto bem-intencionado com a cabeça e levantando a caneca de cerveja.

- Por isso a lei precisa mudar.

- Concedeu-se essa proteção à mulher menor de idade, que depende do consentimento de seu guardião ${ }^{10}$.

8 A autora usa frequentemente em "Dinheiro" uma forma antiga de se escrever "não" em sueco. Ao invés da palavra "inte", mais empregada na atualidade, ela usa "icke". Assim, no trecho original lê-se: "Varför är lagen så orättvis, att en man icke får gifta sig förrän vid tjuguett år, och en kvinna redan vid sexton? sade hon plötsligt."

9 No decorrer do texto, outra característica marcante é o uso recorrente da flexão do verbo no subjuntivo, que não se usa mais na atualidade. Por exemplo, aqui ela usa "vi bleve", ao invés de "vi blir" quando diz "nos tornamos maiores” em "Å nej, utbrast hon otåligt och slog sakta med solfjädern mot sitt knä, jag menar inte så! Jag menar, att inte heller vi borde få gifta oss förrän vi bleve myndiga."

10 Aqui, utiliza-se uma palavra bastante incomum no vocabulário contemporâneo sueco, que é "giftoman", ou seja, a pessoa que dá consentimento para um casamento quando a mulher ou homem não é legalmente um adulto. Vertemos como "guardião". 
- Mas como no mundo pode um guardião decidir se ela pode sentir uma comunhão de vida com o homem que lhe pede a mão, quando ela não o sabe por si mesma? Sim, quando nem se pode dizer que ela teve alguma substância real na vida?

- Substância na vida? Que bobagem! Quantas damas ${ }^{11}$ não vivem até chegar aos sessenta anos sem necessariamente ter substância na vida? Frases modernas! Deixa-as se casarem primeiro, e logo verás a substância na vida: uma casa e um lar para onde ir. Claro que tu mesma viste isso.

- A casa e o lar seriam melhor conduzidos se as mulheres pudessem usar esses quatro ou cinco anos para aprender o que é requerido - ela disse, levantando a mão e apoiando a cabeça nela, enquanto o contemplava com a resignação aborrecida com que se realiza um trabalho que já parece há muito inútil, mas, ainda assim, deve ser terminado. - E, além disso, tu te esqueces completamente de quão preciosos são justamente os anos entre os 16 e os 20 para o desenvolvimento interior.

Parecia que haviam tido essa mesma conversa cem vezes antes, mesmo que fosse uma questão que ela houvera levantado pela primeira vez. Mas isso acontecia, provavelmente, porque ela conhecia seus pensamentos tão bem como se conhece um livro que se tenha decorado: antes que uma pergunta seja pronunciada, já se sabe qual será a resposta.

- Tu te esqueces que há casos em que um casamento rápido... - o senhor ${ }^{12}$ tossiu.

- Não é pelas exceções que se escrevem as leis. E se algo assim pode acontecer, isso não deve ser razão para que a lei deixe dois seres espiritualmente menores se prenderem um ao outro por uma vida inteira e longa. Eu permaneço na dúvida.

- Mas não podes negar que a mulher, em geral, amadurece antes do homem, sim?

- Em termos de intelecto, claro que não. Pelo menos não com os métodos atuais de criação. Ela cresce precocemente. Mas isso é tudo. Ela sempre pensa em que mulher feita já é. Que pode chegar a ser uma esposa qualquer dia desses. - Selma fez uma careta.

- Não sei qual é tua reclamação. Tu mesma tinhas somente dezesseis anos quando te casaste e tudo saiu muito bem.

Ela ruborizou, ficou vermelha como fogo e se levantou da cadeira.

- Acho que tu precisas apenas pensar em quão esquisitona eu era para te dares conta de que as coisas estão de ponta-cabeça - ela respondeu com severidade.

- Para mim, eras uma moça esquisitona realmente encantadora, e ao te olhar agora, é difícil crer que um casamento cedo possa causar danos. Tu cresceste de verdade - disse,

11 A palavra já fora de uso no vocabulário sueco contemporâneo "fruntimmer" é empregada aqui pelo marido de Selma e significa "mulher". Hoje, ela é vista como depreciativa, mas no período talvez não.

12 A autora raramente se refere ao marido de Selma pelo nome, mas sim por "Patron". Nos dicionários de sueco da época, como o Ordbok öfver svenska språket, por nós utilizado, a palavra teria três significados: 1. "patrono", como "patrono das artes"; 2. chefe da casa; 3. dono de uma propriedade ou fábrica ou similar. Optamos pelo uso de "senhor", como em "senhor de terras" e até na acepção anterior da palavra em sueco mesmo, quando "patron" significava "senhor feudal". 
olhando-a com o deleite de que devia gozar um esportista a contemplar um cavalo de raça elegante.

- Isso nunca deveria ter sido dito! - ela se levantou, arrancou de si própria o leque e o jogou no aparador; esse caiu com um chiado sonoro na tampa espelhada. Agora a conversa era nova, pois a calmaria havia passado. - Nenhum dano... ah! Nenhum dano? O que tu pensaste que eu era quando nos casamos? Uma pobre menina que não conhecia nem as pessoas nem a si mesma, que não sabia onde ia e que estava pronta a amar todo mundo, porque via tudo com a mesma ignorância ingênua. Diga-me, nunca sentiste pena de mim? Eu não tinha uma mãe, como os outros, para me dizer...

- Pensas que as mães falam dessas coisas?

O senhor palitou os dentes com indiferença.

- Este deveria ser seu dever! - olhou para ele com surpresa.

- Se querias educar seus filhos dessa maneira, nosso Senhor fez o certo em não te deixar tê-los - disse o senhor, largando o guardanapo amassado com uma sacudida. - Normalmente, considera-se que o dever das mães é deixar suas filhas crescerem de maneira pura e...

- Ah - ela desabafou com aspereza. - Já não aguento escutar mais. Não é que eu tenha um enorme asco por tudo que é sujo, mas precisamente porque eu sei o quão sujo é. Antes, claro, eu não sabia. Ah, é desprezível! Pintamos um quadro tão bonito para nós mesmos... flores puras e raios de sol... e pensamos que tudo é como na nossa própria cabeça. Ah, Deus!... Somos como os homens antes do pecado original: bobos e ignorantes. Não sabemos diferenciar entre o bem e o mal.

- Sim, porque você saberia tudo sobre isso, como... - ele disse de maneira áspera e começou a se enfurecer.

- ... como vocês - satisfez-se ela. - Sim, correto.

Isso soara muito decisivo, com algo do velho tom dela.

- Não, algo de moral há de haver - disse, de maneira depreciativa, e acendeu seu charuto.

- Sim, o mesmo para nós e para vós.

O senhor apenas tragou a brasa de seu charuto. Era irracional o que ela viera dizendo novamente, mas lhe pareceu um pouco difícil dizer isso naquele momento. Com as mulheres, nunca se chega a lugar algum; elas sempre teriam a última palavra. Também sabia havia algum tempo que, quando ela se apossava de algo, não soltava mais. O raciocínio lhe deu um sentimento de mal-estar. O que mais havia querido fazer era evitá-lo.

- Quando te casaste comigo, eu era menor de idade - a tensão de sua alma fez seu batimento cardíaco voar, mas as palavras eram inanimadas como um parágrafo de lei e assim davam voltas na sua cabeça. - Uma nota promissória minha não seria válida e nenhuma 
outra pessoa teria o direito de passar uma, nem de um öre $e^{13}$ sequer, em meu nome ou de conceder algo que no futuro viria a ser meu. Minha pessoa é mais que meu dinheiro. Se eu não era madura o suficiente para administrá-lo, muito menos o era quando se tratava de cuidar de mim mesma. Um menor tampouco deveria deixar seu futuro penhorado como propriedade sua. Essa lógica é simples.

- Sim, vê, não vamos brigar. Tu estás de mau humor. Vem e toma uma taça de champanhe que passa.

- Não. Não quero tua champanhe - ela disse duramente. Teria sido asqueroso de todo modo, mas que ele viesse com a proposta naquele momento, quando ela, pela primeira vez, estava falando daquilo que havia fermentado dentro de si durante anos, serviu apenas para aumentar a amargura.

Mas ele estava cheio e tinha calor, e já que só havia seguido vagamente o que ela havia dito, não podia saber o que agora estava no ar.

- Sim, estás muito cansada - insistiu ele. - Bebe, isso te anima. E uvas! Geralmente tu gostas delas.

- Para, não vou experimentá-las.

Não respondeu, mas soltou a rolha e a deixou voar pelo ar com um estalido. Ela permaneceu quieta ao lado da janela e o contemplou; surgiram duas linhas finas entre suas sobrancelhas, como acontecia sempre que estava irritada. O senhor encheu as duas taças, depois se aproximou e quis lhe dar uma, mas ela repeliu sua mão com tanta violência que ele derramou parte do vinho.

- Como te portas! - disse indignado, colocando a taça dela novamente na mesa e enchendo a sua própria. Mas depois se controlou, pois a indisposição de sua parte apenas a deixava mais inquebrantável, e ele sabia disso.

Depois de ter encontrado a rolha e a ter colocado na garrafa com um golpe, sentou-se na cadeira de balanço para poder vê-la. A emoção havia feito retornar o rubor fortemente delineado a suas bochechas, o que a fazia parecer ligeiramente maquiada. Achava-a bonita. Era este frescor que...

Ela só podia pensar em como não havia nada de mais asqueroso que ver as paixões da juventude transparecerem em um rosto velho.

- Tu ficaste fria e congelada. Vem, para que eu possa te esquentar - ele disse, e estendeu os braços, com o charuto entre o dedo indicador e o médio, totalmente elegante.

- É justamente o que eu queria dizer, que a promessa que te fiz como menina não me prende como mulher.

- Que bobagem!

- Já não posso, me entende? Está terminado.

13 A centésima parte da moeda local, a coroa sueca. 


\section{Referências bibliográficas}

Dahlin, Anders Fredrik. 1850-53. Ordbok öfver svenska språket. Estocolmo. (autopublicação)

Forsås Scott, Helena. 1997. Swedish Women's Writing 1850-1995. Londres: The Athlone Press.

Gabelic Aleksander, Alhem Sven-Erik, Andersson Maria, Brunne Eva, Ericson Emilia, Kanakaris Zandra, Knorn Heidi, et al. 2017. "Svik Inte Flickorna - Stoppa Barnäktenskap". Aftonbladet, March 6. http://www.aftonbladet.se/a/zo4K4. Acessado em 28 de abril de 2017.

Heggestad, Eva. 1991. Fängen och fri. 1800-Talets svenska kvinnliga författare om hemmet, yrkeslivet och konstnärsskapet. Uppsala: Department of literature, Uppsala University.

Hjort, Daniel. 1969. 'Förord'. In Pengar, Ur Från Skåne, Ur Folkliv och Småberättelser Ur Stora Boken och Dagboken. Estocolmo: Albert Bonniers Förlag.

Holm, Birgitta. 2007. Victoria Benedictsson. Estocolmo: Natur och kultur.

Holm, Birgitta. 2008a. "Victoria Benedictsson Bibliografi”. Litteraturbanken. http:/ / litteraturbanken.se/red/forfattare/BenedictssonV/bibliografi/BenedictssonV_bibliografi.pdf.

Holm Birgitta. 2008b. "Victoria Benedictsson/Ernst Ahlgren (1850-1888)". Litteraturbanken. http://litteraturbanken.se/red/forfattare/BenedictssonV/presentation/Bene-

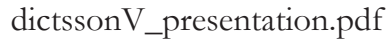

Kalmteg, Lina. 2008. "Först nu är vi redo för Benedictsson". Svenska Dagbladet, December 9. https://www.svd.se/forst-nu-ar-vi-redo-for-benedictsson. Acessado em 28 de abril de 2017.

Länsstyrelsen Östergötland. 2017a "Vad Säger Lagen?” Hedersförtryck.se. http://www. hedersfortryck.se/hedersfortryck/aktenskapstvang-och-barnaktenskap/vad-sager-lagen/. Acessado em primeiro de maio de 2017.

Länsstyrelsen Östergötland. 2017b “Omfattning - Barn- och tvångsäktenskap i Sverige”. Hedersförtryck.se. http://www.hedersfortryck.se/hedersfortryck/aktenskapstvang-ochbarnaktenskap/omfattning-barn-och-tvangsaktenskap-i-sverige/. Acessado em 29 de abril de 2017.

Moberg, Verne. 2007. “Birgitta Holm, Victoria Benedictsson”. Scandinavian Studies, no. 3: 376-80.

Nordenstam, Anna. 2008. "Birgitta Holm, Victoria Benedictsson". Samlaren. Tidskrift för svensk litteraturvetenskaplig forskning. 129: 425-27.

Strömqvist, Liv. 2010. Prins Charles Känsla. Estocolmo: Galago.

Victoria, Benedictsson. 1969. Pengar, Ur Från Skåne, Ur Folkliv Och Smäberättelser Ur Stora Boken Och Dagboken. Estocolmo: Albert Bonniers Förlag.

Willemsen, Charlotte. 2012. "Sanning och arbete. En analys av Victoria Benedictssons författarskap och verk”. Ghent University. http:/ / lib.ugent.be/en/catalog/rug01:001891566. 